\title{
INFLUÊNCIA DOS FATORES EDÁFICOS NA VARIAÇÃO FLORÍSTICA DE FLORESTA ESTACIONAL SEMIDECIDUAL, EM VIÇOSA, MG ${ }^{1}$
}

Antonio Jorge Tourinho Braga ${ }^{2}$, Eduardo Euclydes de Lima e Borges ${ }^{3}$ e Sebastião Venâncio Martins ${ }^{3}$

\begin{abstract}
RESUMO - O objetivo deste estudo foi verificar a possível correlação dos fatores edáficos na distribuição dos indivíduos de espécies arbóreas e a similaridade florística entre as populações, em dois trechos distintos de um fragmento de Floresta Estacional Semidecidual, em Viçosa, MG (2046’ S e 42 $52^{\prime}$ 'W). No trabalho, foram amostrados os indivíduos arbóreos superiores ou iguais a $15 \mathrm{~cm}$ (CAP), presentes em 20 parcelas de $25 \times 10 \mathrm{~m}$, estando metade dessas alocadas (10) em cada trecho de floresta. $\mathrm{Na}$ área das parcelas, foram coletadas amostras de solo $(0-10 \mathrm{~cm})$ e submetidas às análises química e física. Os resultados dos atributos físicos e químicos do solo indicaram variações conforme as mudanças na topografia do terreno. A análise de correspondência canônica (CCA) indicou correlação significativa entre a distribuição das espécies arbóreas avaliadas no perfil topográfico e a fertilidade do solo, enquanto a comparação entre as espécies pertencentes às florestas inicial e avançada apontou baixa similaridade florística. Verificou-se ainda que espécies como Casearia arborea, Ocotea laxa, Myrcia fallax, Siparuna guianensis, Apuleia leiocarpa, Matayba elaeagnoides e Sparattosperma leucanthum estão associadas a solos argilosos mais ácidos, de encostas e com maior teor de alumínio, permitindo o uso delas em programas de recuperação ambiental.
\end{abstract}

Palavras-chave: Similaridade florística; Relação solo-vegetação; Análise de correspondência canônica.

\section{INFLUENCE OF SOIL FACTORS ON FLORISTIC VARIATION IN SEMIDECIDUOUS SEASONAL FOREST IN VIÇOSA, MG}

\begin{abstract}
This study aimed to analyze the possible correlations among soil factors at the tree species distribution and the floristic similarity among populations in two sites of Semideciduous Seasonal Forest, located in Viçosa, $\mathrm{MG}\left(20^{\circ} 46^{\prime} \mathrm{S}\right.$ and $\left.42^{\circ} 52^{\prime} \mathrm{W}\right)$. The tree species with $\leq 15 \mathrm{~cm}$ circumference at breast height $(\mathrm{CBH})$ were sampled in 20 plots of $25 \times 10 \mathrm{~m}$ (10 plots in each site). The soil samples were collected at $0-10 \mathrm{~cm}$ depth and submitted to chemical and physical analysis. The result of the chemical and physical attributes of the soil indicated variations according to topographical gradient. The canonical correspondence analysis (CCA) indicated significant correlation between the distribution of trees species evaluated in the topographic profile and the fertility of the soil. The comparison between species from initial and advanced forests revealed low floristic similarity. Species such as Casearia arborea, Ocotea laxa, Myrcia fallax, Siparuna guianensis, Apuleia leiocarpa, Matayba elaeagnoides and Sparattosperma leucanthum were associated to more acid clayed soils, from hillside and with larger aluminum content, suggesting their use in environmental recovery.
\end{abstract}

Keywords: Floristic similarity; Soil-vegetation relationship; Canonical correspondence analysis.

\footnotetext{
${ }^{1}$ Recebido em 06.09.2014 aceito para publicação em 07.04.2015.

2 Instituto Federal de Educação, Ciência e Tecnologia Baiano, Campus Catu, Catu, BA - Brasil. E-mail: <antonio.braga@catu.ifbaiano.edu.br>.

${ }^{3}$ Universidade Federal de Viçosa, Centro de Ciências Agrárias, Departamento de Engenharia Florestal, Vicosa, MG - Brasil. E-mail: <elborges@ufv.br>e < venancio@ufva.br>.
} 


\section{INTRODUÇÃO}

A heterogeneidade do ambiente florestal, cujos efeitos podem ser observados mesmo no interior de pequenos fragmentos, é resultante tanto da diversidade de fatores que interagem nas comunidades quanto da resposta das espécies a esses fatores, sendo determinantes para que cada local tenha características próprias, possibilitando observar tendências. Estas podem responder a algumas perguntas e gerar várias outras, funcionando com força motriz para novos estudos (RODRIGUES et al., 2007). Desse modo, a necessidade de pesquisas direcionadas a identificar as correlações entre a estrutura da comunidade arbórea e as características ambientais, a exemplo do solo e da topografia, são fundamentais para o conhecimento da ecologia da comunidade arbórea desses fragmentos (MOREIRA etal., 2013). Observando ainda que as variações edáficas por serem fatores seletivos determinam as variações que acontecem na composição florística. Essas variações na composição e estrutura da comunidade vegetal podem ser evidenciadas na biomassa e no estado nutricional da vegetação, como forma de resposta da vegetação às mudanças na disponibilidade de nutrientes do solo (HARIDASAN, 1992). Uma vez que estudos demonstram que solos com baixa disponibilidade de nutrientes selecionam espécies com baixo requerimento nutricional (MEDINA; HUBER, 1992). Assim, a compreensão da interação dos fatores edáficos com a vegetação e da dinâmica de reação dessa comunidade florestal ao ambiente permite analisar a distribuição espacial das espécies no gradiente, além de contribuir, auxiliar e orientar medidas que visem à conservação e manejo adequado de ecossistemas, bem como fornecer informações úteis para a recuperação ambiental dessas comunidades.

Baseado nesse enfoque, este estudo teve como objetivo a possível correlação dos fatores edáficos na distribuição dos indivíduos de espécies arbóreas e a similaridade florística entre as populações em dois trechos distintos de um fragmento de Floresta Estacional Semidecidual no Município de Viçosa, MG.

\section{MATERIAL E MÉTODOS}

O estudo foi realizado na Mata da Agronomia, que pertence à Universidade Federal de Viçosa, em Viçosa, MG (2046' S e 42 $52^{\prime}$ W $)$, com altitude variando de 688 a $782 \mathrm{~m}$. O Município de Viçosa apresenta relevo fortemente ondulado a montanhoso cortado por rios e córregos afluentes do rio Doce, em que nos vales estreitos e úmidos predominam duas classes de solos, o Latossolo Vermelho-Amarelo Álico, presentes nos topos; e o Argissolo Vermelho-Amarelo Câmbico, com ocorrência tanto nas encostas das elevações quanto nas feições do relevo denominadas terraços fluviais (VALVERDE, 1958; RESENDE et al., 1988).

O clima da região é do tipo Cwb (Köppen), mesotérmico com verões chuvosos e invernos frios e secos. A temperatura média anual é de $19^{\circ} \mathrm{C}$, e a umidade relativa do ar varia em torno de $80 \%$, sendo a precipitação média anual de 1.314 mm (CASTRO et al., 1983). A vegetação da Mata da Agronomia, com mais de 50 anos de regeneração natural, é caracterizada como Floresta Estacional Semidecidual Montana (VELOSO et al., 1991), compondo um mosaico de diferentes estádios sucessionais, após a cobertura vegetal original ter sido substituída, por meio do corte raso, por plantio sequencial de café e pastagem.

Os trechos escolhidos para o estudo tiveram o mesmo histórico de perturbação, diferenciando quanto à regeneração, que sucedeu em períodos distintos, apresentando, portanto, diferentes estádios de regeneração. O primeiro, caracterizado como floresta inicial, encontra-se em processo de regeneração, substituindo a pastagem há aproximadamente 30 anos, e localiza-se nas coordenadas $20^{\circ} 46.105^{\prime} \mathrm{S}$ e $42^{\circ} 52.026^{\prime} \mathrm{W}$, com altitude variando de 688 a $737 \mathrm{~m}$. O segundo, com mais de 50 anos, foi caracterizado como floresta avançada, localiza-se nas coordenadas $20^{\circ} 46.197^{\prime} \mathrm{S}$ e $42^{\circ} 52.061^{\prime} \mathrm{W}$, com a altitude alterando de 708 a $782 \mathrm{~m}$.

A listagem florística foi obtida a partir de uma amostragem fitossociológica de todos os indivíduos arbóreos presentes nas 10 parcelas permanentes (25 $\mathrm{x} 10 \mathrm{~cm}$ ), alocadas em intervalos de $5 \mathrm{~m}$ em cada trecho da floresta, de acordo com o método de parcelas (MUELLER-DOMBOIS; ELLENBERG, 1974), totalizando, com os dois trechos, uma área amostral de 0,5 ha (BRAGA et al., 2011).

As amostras de solo foram coletadas de forma aleatória em cada parcela, com o auxílio de um trado holandês na camada de 0 a $10 \mathrm{~cm}$, totalizando 20 amostras coletadas, cada uma composta de 10 subamostras. Após a coleta, as amostras foram submetidas às análises química (rotina e matéria orgânica) e física no laboratório do Departamento de Solos da Universidade Federal de Viçosa. 
A comparação florística entre os trechos de florestas estudados foi realizada elaborando uma matriz de presença e ausência de espécies, a partir da qual foi construído um dendrograma de similaridade entre todas as parcelas da floresta inicial e avançada, com todas as espécies amostradas, utilizando o programa FITOPAC 1 (SHEPHERD, 1996). Para a elaboração do dendrograma, foram utilizados o índice de similaridade de Sörensen (BROWER; ZAR, 1984) e o método de agrupamento pela média de grupo (UPGMA).

Para possibilitar a análise de ordenação direta de gradientes, explicando a distribuição das espécies em relação às variáveis ambientais, foi utilizada a análise de correspondência canônica (CCA), empregando o programa PC-ORD (McCUNE; MEFFORD, 1999).

Duas matrizes foram elaboradas, uma de vegetação contendo a densidade de espécies por parcela e outra contendo os dados de solos. Na matriz vegetacional, foram consideradas as espécies com cinco ou mais indivíduos no levantamento total, o que correspondeu a 41 espécies, enquanto a matriz de variáveis ambientais incluiu 14 variáveis edáficas $(\mathrm{pH}, \mathrm{K}, \mathrm{Ca}, \mathrm{Mg}, \mathrm{Al}, \mathrm{SB}$, t, V, MO e P-rem). O nível de significância do principal eixo de ordenação canônica foi avaliado pelo teste de permutação Monte Carlo (TER BRAAK; PRENTICE, 1988).

\section{RESULTADOS}

\subsection{Caracterização dos solos nos trechos de floresta}

A análise granulométrica dos solos apresentou predominância da textura argilosa em $50 \%$ das amostras das parcelas localizadas nas extensões de encosta, enquanto nas parcelas distribuídas pelas baixadas a textura variou entre franco-argilosa e argilo-arenosa (Tabela 1).

A análise por trecho de floresta indicou que os solos das florestas inicial e avançada diferenciaram quanto à classe textural, apresentando, respectivamente, textura argilosa e argilo-arenosa (Tabela 1). Ambas as florestas mostraram a mesma quantidade da fração argila (43 dag/kg), diferenciando-se nas demais frações (areiagrossa, areia-fina e silte), em que os maiores valores encontrados foram na floresta avançada.

Ao avaliar as análises químicas do solo, verificou-se aumento nos teores de K, Ca e Mg e na saturação por bases (SB) do topo para a baixada (Tabela 1). Com relação ao fósforo, os maiores teores foram encontrados nas parcelas situadas no topo das encostas (parcelas 1 e 20), porém, ao considerar todo o gradiente topográfico, comprovou-se que não há um padrão de variação definido desse nutriente. O teor e saturação por alumínio aumentaram da base para o topo, enquanto o $\mathrm{pH}$ teve tendência oposta, indicando a presença dos solos mais ácidos no topo das encostas.

Os resultados da composição do solo de cada trecho de floresta demonstram que no solo da floresta inicial estão os maiores teores dos macronutrientes (K, Ca e $\mathrm{Mg}$ ) e os menores teores de alumínio, o que resulta em valores muito superiores de soma de bases (SB), saturação por bases (V) e o pH mais elevado que o encontrado na floresta avançada. Entretanto, é o solo ácido da floresta avançada que possui o maior teor de matéria orgânica.

\subsection{Similaridade florística}

O dendrograma que permite visualizar as relações florísticas, gerado pela análise de agrupamento utilizando a média de grupo (UPGMA), mostra que foram formados dois grandes grupos de parcelas, com $33 \%$ de similaridade (Figura 1).

Houve nítida diferença entre os trechos de florestas mostrados no dendrograma, em que o grupo representado pelas parcelas de 11 a 20, alocadas na floresta avançada, apresentou $47 \%$ de similaridade, enquanto o outro grupo formado com as parcelas de 4 a 10, alocados na floresta inicial, destacou-se ao mostrar similaridade florística de $49 \%$. Observou-se, ainda, pequeno grupo, que curiosamente sobressai do primeiro, formado pelas parcelas 1, 2 e 3, alocadas na floresta inicial, que apresentou similaridade de $33 \%$ e pode ser considerado um trecho de transição.

Os mais altos índices de similaridade foram observados entre as parcelas pertencentes aos mesmos trechos de floresta, embora isso não tenha, necessariamente, configurado a proximidade física entre essas parcelas, como se nota na alta similaridade florística de $65 \%$ entre as parcelas 4 e 6 da floresta inicial e de $68 \%$ entre as parcelas 16 e 20 da floresta avançada.

Portanto, comparando os trechos estudados, verificou-se o baixo índice de similaridade entre as comunidades das florestas inicial e avançada, revelando a heterogeneidade do componente arbóreo.

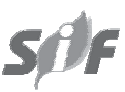

Revista Árvore, Viçosa-MG, v.39, n.4, p.623-633, 2015 


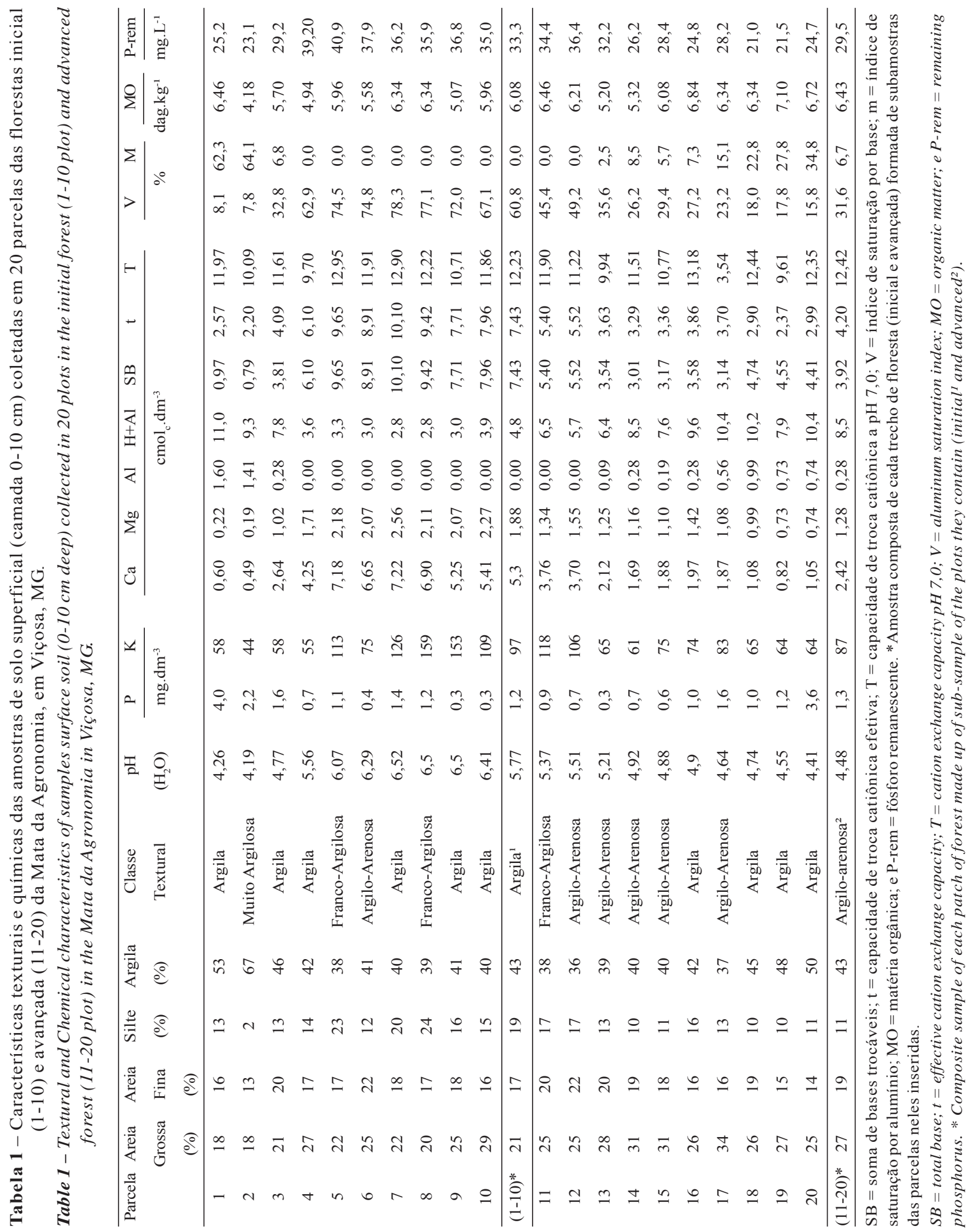




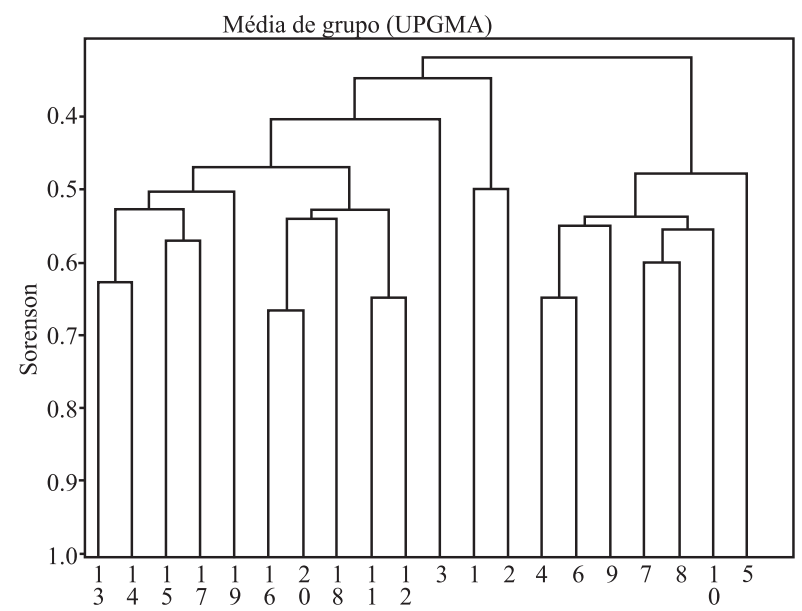

Figura 1 - Dendrograma obtido pelo método da média de grupo (UPGMA), com base no índice de Sörensen, para dados de presença e ausência das espécies das florestas inicial (parcelas de 1 a 10) e avançada (parcelas de 11 a 20) na Mata da Agronomia, Viçosa, MG.

Figure 1 -Dendrogram obtained by average linkage method (UPGMA), based on the Sörensen index, for the presence and absence data of the species of initial forest (1 to 10 plot) and advanced forest (11 to 20 plot) in the Mata da Agronomia, Viçosa, MG.

\subsection{Correlação entre ambiente e vegetação}

Os autovalores da análise de correspondência canônica (CCA) nos dois primeiros eixos de ordenação foram de 0,559 (eixo 1) e 0,358 (eixo 2), com o primeiro eixo explicando $23,5 \%$ e o segundo, $15,1 \%$ da variância total acumulada na média ponderada das 41 espécies, com respeito às variáveis ambientais.

As correlações espécie-ambiente produzidas pela CCA foram altas nos dois primeiros eixos $(0,983$ no primeiro eixo e 0,973 no segundo). O teste de permutação de Monte Carlo foi significativo a $1 \%$ de probabilidade, indicando que a abundância das espécies e as variáveis ambientais foram correlacionadas com o primeiro e o segundo eixo da ordenação. As variáveis ambientais mais correlacionadas em ordem decrescente com o primeiro eixo foram saturação por bases, $\mathrm{pH}$, cálcio $(\mathrm{Ca})$ e magnésio (Mg) (Tabela 2).

Observando as correlações ponderadas, estas também mostraram interações fortes entre as variáveis analisadas, merecendo destaque as altas correlações positivas, com $52 \%$ dos valores acima de 0,900 , evidenciando as altas correlações entre o Ca e a capacidade de troca catiônica efetiva (t), o Ca e a saturação por bases (V), o pH e o $\mathrm{V}$ e ressaltando as altas correlações negativas entre $\mathrm{Mg}$ e Al e Al e V.

O diagrama de ordenação das parcelas no primeiro eixo (Figura 2) mostra claramente a divisão de dois grupos, um primeiro formado pelas parcelas alocadas no trecho de floresta avançada (P11 a P20), com autovalores positivos para esse eixo, estando aliadas a esse as parcelas de P1, P2 e P3 e um segundo grupo formado pela maioria das parcelas alocadas no trecho de floresta inicial

Tabela 2 - Análise de correspondência canônica (CCA) da abundância de 41 espécies amostradas em 20 parcelas da Mata da Agronomia: coeficientes canônicos e correlações ponderadas para variáveis ambientais utilizadas na análise. Correlações com valores absolutos superiores a 0,5 estão indicadas em negrito.

Table 2 - Canonical correspondence analysis (CCA) of the abundance of 41 species sampled in 20 plots in Mata da Agronomia: canonical coefficient and weighted correlations for the environmental variables utilized in the analysis. Correlations with values higher than 0.5 are in evidence.

\begin{tabular}{|c|c|c|c|c|c|c|c|c|c|c|c|c|}
\hline \multirow[t]{2}{*}{$\begin{array}{l}\text { Variável } \\
\text { ambiental }\end{array}$} & \multicolumn{2}{|c|}{$\begin{array}{l}\text { Correlações } \\
\text { ponderadas }\end{array}$} & \multirow[b]{2}{*}{$\mathrm{pH}$} & \multirow[b]{2}{*}{$\mathrm{K}$} & \multirow[b]{2}{*}{$\mathrm{Ca}$} & \multirow[b]{2}{*}{$\mathrm{Mg}$} & \multirow[b]{2}{*}{ Al } & \multirow[b]{2}{*}{ SB } & \multirow[b]{2}{*}{$\mathrm{t}$} & \multirow[b]{2}{*}{ V } & \multirow[b]{2}{*}{ MO } & \multirow[b]{2}{*}{ P-rem } \\
\hline & Eixo 1 & Eixo 2 & & & & & & & & & & \\
\hline $\mathrm{pH}$ & $-0,914$ & $-0,087$ & - & & & & & & & & & \\
\hline $\mathrm{K}$ & $-0,636$ & $-0,097$ & 0,819 & - & & & & & & & & \\
\hline $\mathrm{Ca}$ & $-0,886$ & 0,002 & 0,951 & 0,762 & - & & & & & & & \\
\hline MG & $-0,886$ & $-0,251$ & 0,961 & 0,747 & $\mathbf{0 , 9 3 8}$ & - & & & & & & \\
\hline Al & 0,753 & 0,403 & $-0,781$ & $-0,573$ & $-0,745$ & $-0,854$ & - & & & & & \\
\hline SB & $-0,866$ & $-0,208$ & 0,924 & 0,755 & 0,943 & 0,931 & $-0,723$ & - & & & & \\
\hline $\mathrm{T}$ & $-\mathbf{0 , 8 8 0}$ & 0,026 & 0,951 & 0,778 & 0,996 & 0,933 & $-0,700$ & 0,945 & - & & & \\
\hline V & $-0,939$ & $-0,042$ & 0,976 & 0,752 & 0,978 & $\mathbf{0 , 9 5 7}$ & $-0,812$ & 0,932 & 0,968 & - & & \\
\hline $\mathrm{MO}$ & 0,332 & $-0,335$ & $-0,154$ & 0,109 & $-0,110$ & $-0,063$ & 0,120 & 0,052 & $-0,087$ & $-0,191$ & - & \\
\hline P-rem & $-\mathbf{0 , 8 3 7}$ & 0,100 & 0,844 & 0,844 & 0,886 & 0,821 & $-0,774$ & 0,762 & 0,861 & 0,917 & $-0,314$ & - \\
\hline
\end{tabular}




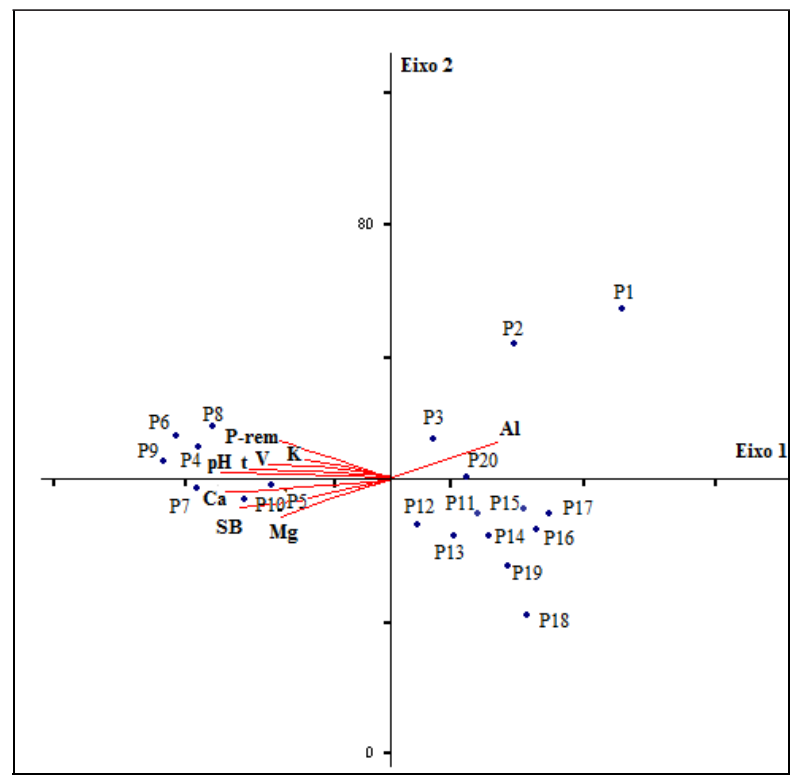

Figura 2 - Análise de correspondência canônica: diagrama de ordenação das parcelas das florestas inicial (1-10) e avançada (11-20) na Mata da Agronomia, Viçosa, MG, baseada na distribuição de 41 espécies arbóreas em 20 parcelas. As parcelas estão representadas pela numeração correspondente e as variáveis ambientais, por vetores.

Figure 2-Canonical correspondence analysis: ordering diagram of the plots in the initial forest (1-10) and advanced (11-20) in the Mata da Agronomia, Viçosa, MG, based on the distribution of 41 tree species in 20 plots. The plots are represented by the corresponding numeration and the environmental variables by vectors.

(P4 a P10), que apresentam autovalores negativos no primeiro eixo.

Das parcelas alocadas na floresta inicial, as P1, P2 e P3 passam a ser consideradas uma zona de transição, tendência observada também no gráfico de similaridade florística. Essas parcelas apresentam autovalores positivos, tanto no primeiro quanto no segundo eixo, assim como na parcela 20. Todas essas parcelas mencionadas encontram-se na mesma situação de encosta no perfil do terreno e estão correlacionadas com solos mais ácidos, com maiores concentrações de alumínio (Al), conforme se observa no gradiente edáfico da esquerda para a direita.

As parcelas de P4 a P10 apresentam autovalores negativos no primeiro eixo, e as parcelas P5, P7 e P10 também apresentam autovalores negativos no segundo eixo, estando correlacionadas com solos com maior concentração de Ca e Mg e maior soma de bases trocáveis (SB). Enquanto as demais parcelas estão correlacionadas com um pH mais elevado, ou seja, menos ácido, observa-se, ainda, aumento progressivo na capacidade de troca catiônica, na saturação por bases e nos teores de potássio e do fósforo remanescente. Essas parcelas, pertencentes à floresta inicial, estão instaladas na posição de baixada e terço inferior da encosta do terreno.

A ordenação das espécies pela CCA (Figura 3) indica que espécies como Casearia arborea, Ocotea laxa, Myrcia fallax, Siparuna guianensis, Apuleia leiocarpa, Matayba elaeagnoides, Sparattosperma leucanthum e Protium warmingianum são mais abundantes em solos mais ácidos, de encostas e com maior teor de alumínio. A maior concentração dessas espécies ocorreu justamente nas parcelas de 1 a 3 , situadas no trecho de floresta inicial.

Na outra extremidade do gradiente, concentra-se o grupo de espécies formadas por Anadenathera peregrina, Albizia polycephala, Astronium graveolen, Allophylus sericeus, Cecropia glaziovii, Croton urucurana, Cabralea canjerana, Copaifera langsdorfii, Nectandra saligna, Rolinea sp. e Vernonanthura diffusa, que ocorreram em ambiente com $\mathrm{pH}$ mais elevado, maior concentração de potássio (K) e de fósforo remanescente e maiores t e V. Esse grupo apresentou maior densidade de indivíduos na floresta inicial, como as espécies pioneiras típicas C. glaziovii, C. Urucurana e V. diffusa, que foram exclusivas desse trecho; espécies secundárias iniciais, como $A$. peregrina, $A$. sericeus, $N$. saligna e Rolinea sp.; e, curiosamente, espécies tardias, como C. canjerana, que apresentou o mesmo comportamento observado por S. guianensis.

\section{DISCUSSÃO}

\subsection{Caracterização dos solos nos trechos de floresta}

As classes de solos observadas nas florestas, inicial e avançada, correspondem aos tipos de solos encontrados na região, onde predominam os latossolos. Segundo Ker (1997), os solos assim designados, além de profundos, de coloração relativamente homogênea com matizes avermelhadas e, ou, amareladas, apresentam distribuição mais ou menos uniforme de argila ao longo do perfil, elevada estabilidade de agregados e baixo teor de silte em relação à argila. 


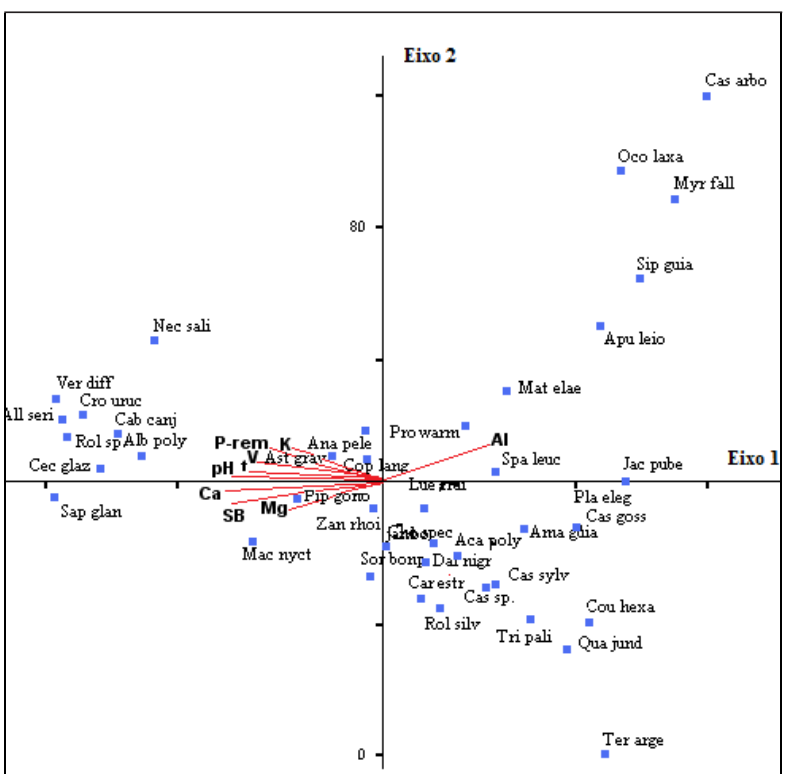

*As 41 espécies arbóreas, com mais de cinco indivíduos, amostradas nas florestas inicial e avançada com as abreviações utilizadas na CCA: Acacia polyphylla DC. (Aca poly); Albizia polycephala (Benth.) Killip (Alb poly); Allophylus sericeus Radlk. (All seri); Aloysia virgata (Ruiz \& Pavon) A. Juss. (Ama guia); Anadenathera peregrina Speg. (Ana pele); Apuleia leiocarpa Macbride (Apu leio); Astronium graveolens Jacq. (Ast grav); Cabralea canjerana (Vell.) Mart. (Cab canj); Cariniana estrellensis Kuntze (Car estr); Casearia arbórea (Rich.) Urb. (Cas arbo); Casearia gossypiosperma Briq. (Cas goss); Casearia sp. (Cas sp.); Casearia sylvestris Sw. (Cas sylv); Cecropia glaziovii Snethl. (Cec glaz); Ceiba speciosa (A. St.-Hil.) Ravenna (Cho spec); Copaifera langsdorffii Desf. (Cop Lang); Coutarea hexandra (Jacq.) K. Schum. (Cou hexa); Croton urucurana Baill. (Cro uruc); Dalbergia nigra Allem. Ex Benth. (Dal nigr); Eugenia sp. (Eug sp); Jacaranda puberula Cham. (Jac pube); Luehea grandiflora Mart. \& Zucc. (Lue gran); Machaerium nyctitans (Vell.) Benth. (Mac nyct); Matayba elaeagnoides Radlk. (Mat elae); Myrcia fallax DC. (Myr fall); Nectandra saligna Nees (Nec Sali); Ocotea laxa Mez (Oco laxa); Piptadenia gonoacantha Macbride (Pip gono); Platypodium elegans Vog. (Pla elegans); Protium warmingianum March. L. (Pro warm); Qualea jundiahy Warm. (Qua jund); Rollinia silvatica Mart. (Rol silv); Rollinia sp. (Rol sp); Sapium glandulatum

Figura 3 - Análise de correspondência canônica: diagrama de ordenação das espécies baseada na distribuição da densidade nas 20 parcelas das florestas inicial e avançada da Mata da Agronomia, Viçosa, MG. As variáveis ambientais estão representadas por vetores e as espécies, pelos nomes abreviados (*).

Figure 3-Canonical correspondence analysis: ordering diagram of the species based on the density distribution in 20 plots in the initial and advanced forest in the Mata da Agronomia, Viçosa, MG. The environmental variables are represented by vectors and the species by their abbreviated names (*).

A topografia acidentada da região favorece grandes perdas das partículas mais leves devido às elevadas taxas de erosão superficial nos períodos de chuvas na região, intensificada pela saturação dos solos localizados na vertente íngreme. Assim, com o excesso hídrico, essas partículas são depositadas na parte mais baixa da encosta, fazendo surgir um gradiente de textura mais fina encosta abaixo (RESENDE et al., 1988). Logo, o aumento na fertilidade do solo ao longo dos gradientes topográficos é maior na base das encostas devido ao transporte de material provindo das partes altas (BOTREL et al., 2002). Assim, Martins et al. (2003), ao avaliarem as variações edáficas em outra Floresta Estacional Semidecidual, também localizada na região de Viçosa, $\mathrm{MG}$, constataram aumento nos teores $\mathrm{K}, \mathrm{Ca}$ e $\mathrm{Mg}$ e na saturação por bases (SB) do topo para a baixada, semelhante ao apresentado neste estudo.

Assim como no estudo de Pinto et al. (2009), que também foi realizado em dois trechos de uma Floresta Estacional Semidecidual na mesma região de Viçosa, os solos das florestas inicial e avançada apresentam características edáficas distintas. Contudo, diferentemente do atual trabalho, foi no trecho de floresta inicial que ocorreram os solos mais ácidos e com baixa fertilidade, sendo os solos da floresta intitulada madura, onde ocorrem os solos mais férteis. Portanto, pode-se afirmar que a fertilidade e qualidade do solo contribuem para o estabelecimento e desenvolvimento das espécies.

Rodrigues et al. (2007) verificaram em seu estudo realizado em representações da Floresta Estacional Semidecidual Aluvial e Floresta Estacional Semidecidual Montana, no Município de Luminárias, Minas Gerais, que os resultados do $\mathrm{pH}$, soma de bases e a relação $\mathrm{Ca}+\mathrm{Mg} / \mathrm{Al}$ diminuíram ao longo da mudança do gradiente (Argissolo Vermelho -> Cambissolo) e aumento da altitude, indicando que a topografia provavelmente influenciou as características químicas e físicas do solo.

Os resultados encontrados no estudo de Rodrigues et al. (2007) reforçam a teoria do aumento da acidez do solo proveniente do maior teor de $\mathrm{Al}$ e do decréscimo nos teores de $\mathrm{K}, \mathrm{Ca}$ e $\mathrm{Mg}$ proporcional ao aumento da declividade do terreno. Entretanto, diferenciam dos resultados deste estudo, quando indicam que os solos do perfil mais íngreme da encosta são mais rasos, mais arenosos e, consequentemente, mais fortemente drenados, o que ocasionou maior concentração de Al e baixos níveis de $\mathrm{Ca}+\mathrm{Mg}$. Os perfis desta pesquisa são mais íngremes, compostos de solos mais argilosos, desassociando, portanto, a relação da classe textural do perfil topográfico do grau de acidez.

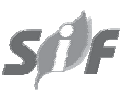

Revista Árvore, Viçosa-MG, v.39, n.4, p.623-633, 2015 


\subsection{Similaridade florística}

A maior similaridade florística observada na floresta avançada, em um pequeno trecho tratado como uma área em estádio de transição da floresta inicial, dar-se-á, principalmente, pela presença de espécies como Apuleia leiocarpa, Casearia gossypiosperma, Jacaranda puberula e, principalmente, Siparuna guianensis, espécie muito generalista, inclusive no Cerrado, bastante encontrada em florestas mais maduras.

É importante destacar que as três parcelas que formam esse pequeno grupo estão alocadas na encosta do terreno, ou seja, no extremo do gradiente topográfico, que diferencia essas parcelas das demais alocadas no mesmo trecho de floresta inicial e as aproxima da situação de topografia mais acidentada do trecho de floresta avançada, onde, nesta última, o gráfico não apresenta diferença nítida entre os grupos de parcelas. Assim, a encosta pode ser caracterizada como um ambiente de transição, tanto em termos edáficos quanto de arranjo espacial das espécies arbóreas, conforme também foi observado por Martins et al. (2003).

A heterogeneidade florística do componente arbóreo está associada a diversos fatores, que vão desde o perfil topográfico e a disponibilidade de nutrientes no solo ao estádio sucessional. Este último, por sua vez, está relacionado diretamente com a quantidade de luz e retenção de umidade no solo, fatores decisivos no recrutamento de espécies adaptadas a essas condições.

Segundo Bertoni e Martins (1997), a heterogeneidade entre trechos de floresta pode ser resultante de variações das condições ambientais, das preferências ecológicas de cada espécie e, também, dos diversos graus de perturbação antrópica. Machado et al. (2004) afirmaram que a heterogeneidade deve ser levada em consideração quando se buscam meios de conservar a diversidade biológica dos remanescentes florestais.

\subsection{Correlação entre ambiente e vegetação}

Os autovalores da CCA encontrados estão dentro dos padrões, quando confrontados com os de trabalhos já desenvolvidos em Floresta Estacional Semidecidual na região de Viçosa (MARTINS et al., 2003; PINTO et al., 2009), sendo considerados altos quando comparados com resultados de estudos também realizados em Florestas Estacionais Semideciduais, em outras localidades do Estado de Minas Gerais (CAMARGOS et al., 2008; RODRIGUES et al., 2007;
SOUZA et al., 2003; BOTREL et al., 2002; ESPÍRITOSANTO et al., 2002). Os resultados indicam ainda a ocorrência de espécies restritas a determinados ambientes ao longo do perfil topográfico, amostrados nas parcelas. Esse nítido gradiente ambiental formado corresponde não apenas a cada trecho de floresta, mas, principalmente, à topografia do terreno, com espécies nitidamente restritas a ambientes de encostas e outras aos de baixadas.

As espécies C. arborea, O. laxa, M. fallax, S. guianensis, A. leiocarpa, M. elaeagnoides, S. leucanthum e $P$. warmingianum são classificadas como secundárias. Entretanto, destaca-se o comportamento de S. guianenses, que, embora seja classificada como secundária, se concentrou na floresta inicial, tanto neste quanto no estudo realizado por Pinto et al. (2009).

As características apresentadas pelas espécies anteriormente citadas podem sugerir o uso delas em programas de recuperação ambiental, principalmente em áreas muito antropofizadas, onde a recomposição da vegetação deve privilegiar espécies mais adaptadas a áreas com condições de baixa fertilidade.

Já a espécie C. canjerana, que apresentou o mesmo comportamento observado em S. guianensis, pode ser encontrada, segundo Lorenzi (2000), em todas as formações florestais. Embora seja mais comum em floresta primária, essa espécie também pode ser encontrada com comportamentos pioneiro e secundário, por ser heliófita e indicar nítida preferência por solos argilosos e úmidos de encostas. Segundo esse mesmo autor, espécies pioneiras como C. urucurana e C. glaziovii são encontradas em capoeiras e capoeirões, com distribuição contínua e regular, e sobre encostas suaves e fundo de vales, onde o solo é argiloso, úmido e mais rico em matéria orgânica, como no caso do trecho de floresta inicial, onde foram encontradas.

Espécies como Piptadenia gonoacantha, Zanthoxylum rhoifolium, Machaerium nyctitans e Sorocea bonplandii, encontradas em ambos os trechos de floresta, mostraram-se correlacionadas com os sítios com melhores condições de fertilidade, principalmente em relação a $\mathrm{Ca}$ e $\mathrm{Mg}$, e maior soma de base (SB). Comportamento semelhante ao apresentado por P. gonoacantha foi observado por Martins et al. (2003), em que a espécie se mostrou adaptada a solos de melhor fertilidade, textura mais arenosa e correlacionados a situações características de baixada e terço inferior da encosta. 
Ainda de acordo com Carvalho (1994), $P$. gonoacantha, por ser espécie considerada generalista, ocorre tanto em solos pobres quanto em solos férteis, embora tenha apresentado maior crescimento em solos de fertilidade de média a elevada, em avaliações realizadas em plantios experimentais.

Muito embora as condições edáficas do ambiente possam determinar ou favorecer o aparecimento ou estabelecimento de determinadas espécies, é necessário cautela na interpretação da distribuição delas sobre o perfil topográfico, pois, segundo Camargos et al. (2008), variáveis como as condições de luz ou, mesmo, os fatores de dispersão das espécies nem sempre são facilmente perceptíveis ou mensuráveis, sendo algumas espécies sensíveis a essas variáveis, de forma interativa e não isoladamente.

Esse conjunto de resultados, a exemplo dos encontrados nos estudos de Pinto et al. (2009) e Martins et al. (2003), confirma as considerações sobre a relação entre fatores edáficos e vegetação feitas por Clark (2002), nas quais destaca o papel da topografia na modificação de fatores edáficos e na determinação de distribuição das espécies.

Logo, os resultados apresentados, além de demonstrarem a predileção de certas espécies por determinados nutrientes do solo, reforçam a ideia de que a distribuição das espécies está relacionada mais com a posição topográfica e com o solo a ela associado que ao estágio sucessional em que a floresta se encontra.

\section{CONCLUSÃO}

As propriedades físicas e químicas do solo variam conforme alterações no perfil topográfico da área.

Solos mais ácidos, argilosos, menos férteis e com altos teores de Al encontram-se no topo da encosta, invertendo a situação à medida que o perfil se aproxima da região de baixada, onde o solo é menos ácido e mais fértil.

A classe textural do solo presente no perfil topográfico não está associada a determinado grau de acidez.

As comunidades das florestas inicial e avançada apresentam baixo índice de similaridade florística associado a fatores, como o perfil topográfico, a disponibilidade de nutrientes no solo e o estádio sucessional.
Espécies como Casearia arborea, Ocotea laxa, Myrcia fallax, Siparuna guianensis, Apuleia leiocarpa, Matayba elaeagnoides e Sparattosperma leucanthum são mais abundantes em solos mais ácidos, de encostas e com maior teor de alumínio.

\section{AGRADECIMENTOS}

Ao Conselho Nacional de Desenvolvimento Científico e Tecnológico (CNPq), pelo auxílio a esta pesquisa e pela bolsa de estudos.

\section{REFERÊNCIAS}

BERTONI, J.E.A.; MARTINS, F.R. Composição florística de uma floresta ripária na Reserva Estadual de Porto Ferreira, SP. Acta

Botanica Brasilica, v. 1, n.1, p.17-26, 1987.

BOTREL, R.T.; OLIVEIRA FILHO, A.T., RODRIGUES, L.A.; CURI, N. Composição florística e estrutura da comunidade arbórea de um fragmento de floresta estacional semidecidual em Ingaí, MG, e a influência de variáveis ambientais na distribuição das espécies. Revista Brasileira de Botânica, v.25, n.2, p.195-213, 2002.

BRAGA, A. J. T.; BORGES, E. E. L.; MARTINS, S. V. Florística e estrutura da comunidade arbórea de uma Floresta Estacional Semidecidual secundária em Viçosa, MG. Revista Árvore, v.35, n.3, p.493-503, 2011.

BROWER, J.E.; ZAR, J.H. Field and laboratory methods for general ecology. Dubuque: WmC Publishers, 1984. $226 \mathrm{p}$.

CAMARGOS, V.L.; SILVA, A.F.; MEIRA NETO, J.A.A.; MARTINS, S.V. Influência de fatores edáficos sobre variações florísticas na Floresta Estacional Semidecídua no entorno da Lagoa Carioca, Parque Estadual do Rio Doce, MG, Brasil. Acta Botanica Brasilica, v.22, n.1, p.75-84, 2008.

CARVALHO, P.E.R. Espécies florestais brasileiras: recomendações silviculturais, potencialidades e uso da madeira. Colombo: Embrapa-CNPF. Brasília: Embrapa-SPI, 1994. 639p. 
CASTRO, P.S.; VALENTE, O.F.; COELHO, D.T. Interceptação da chuva por mata natural secundária na região de Viçosa, MG. Revista Árvore, v.7, n.1, p.76-88, 1983.

CLARK, D.B. Los fatores edáficos y la distribución de las plantas. In: GUARIGUATA M.R.; KATTAN, G.H. Ecologia y conservatión de bosques neotropicais. Cartago: Ediciones LUR, 2002. p.192-221.

ESPÍRITO-SANTO, F. D. B.; OLIVEIRA-FILHO, A. T.; MACHADO, E. L. M.; SOUZA, J. S.; SOUZA, J. S.; FONTES, M. A. L.; MARQUES, J. J. G. S. M. Variáveis ambientais e distribuição de espécies arbóreas em um remanescente de Floresta Estacional Semidecidual Montana no campus da Universidade Federal de Lavras, MG. Acta

Botanica Brasilica, v. 16, n.3, p.331-356, 2002.

KER, J.C. Latossolos do Brasil: Uma revisão.

Geonomos, v.5, n.1, p.17-40, 1997.

HARIDASAN, M. Observations on soils, foliar nutrient concentrations and floristic composition of cerrado sensu stricto and cerradão communities in central Brasil. In: FURLEY, P.A.; PROCTOR, J.; RATTER, J.A. (Ed.) Nature and dynamics of forest-savanna boundaries. London: Chapman and Hall, 1992. p.309-348.

LORENZI, H. Árvores brasileiras: manual de identificação e cultivo de plantas arbóreas do Brasil. 3.ed. Nova Odessa: Plantarum, 2000. v.1. $368 \mathrm{p}$.

MACHADO, E. L. M.; OLIVEIRA-FILHO, A. T.; CARVALHO, W. A. C.; SOUZA, J. S.; BORÉM, R. A. T.; BOTEZELLI, L. Análise comparativa da estrutura e flora do compartimento arbóreoarbustivo de um remanescente florestal na fazenda Beira Lago, Lavras, MG. Revista Árvore, v.28, n.4, p.499-516, 2004.

MARTINS, S. V.; SILVA, N. R. S.; SOUZA, A. L.; MEIRA-NETO, J. A. A. Distribuição de espécies arbóreas em um gradiente topográfico de Floresta Estacional Semidecidual em Viçosa, MG. Scientia Florestalis, v.64, n.1, p.172-181, 2003.

McCUNE, B.; MEFFORD, M.J. PC-ORD version 4.0, Multivariate analysis of

Revista Árvore, Viçosa-MG, v.39, n.4, p.623-633, 2015 ecological data; Users guide. Glaneden Beach: MjM Software Desing. 1999. 237p.

MEDINA, E.; HUBER, O. The role of biodiversity in the functioning of savanna ecossystems. In: WALKER, B.H. (Ed.) Determinants of tropical savannas. Oxford: IRL Press, 1992. p.139-158.

MOREIRA, A. M.; MENINO, G. C. O.; SANTOS, R. M.; PIFANO, D. S.; BORÉM, R. A. T.; ALMEIDA, C. A. M.; DOMINGOS, D. Q. Composição florística e estrutura da comunidade arbórea de um fragmento de Floresta Estacional Semidecidual em Coqueiral, MG, Brasil. Revista Brasileira de Biociências, v.11, n.1, p.43$51,2013$.

MÜller-DOMBOIS, D.; ELLENBERG, H. Aims and methods of vegetation ecology. New York: John Wiley e Sons, 1974. 547p.

PINTO, S. I. C.; MARTINS. S. V.; BARROS, N.F.; DIAS, H.C.T. Ciclagem de nutrientes em dois trechos de Floresta Estacional Semidecidual na reserva florestal Mata do Paraíso em Viçosa, MG, Brasil. Revista Árvore, v.33, n.4, p.653-663, 2009.

RESENDE, M.; CURI, N.; SANTANA, D.P. Pedologia e fertilidade do solo: interações e interpretações. Brasília: Ministério da Agricultura. Lavras: UFLA/FAEPE, 1988. 81p.

SHEPHERD, G.J. Fitopac 1.0: manual do usuário. Campinas: Universidade de Campinas, 1996. 89p.

RODRIGUES, L. A.; CARVALHO, D. A.; OLIVEIRA-FILHO, A. T.; CURI, N. Efeitos de solos e topografia sobre a distribuição de espécies arbóreas em um fragmento de floresta estacional semidecidual em Luminárias, MG. Revista Árvore, v.31, n.1, p.25-35, 2007.

SOUZA, J. S.; ESPÍRITO-SANTO, F. D. B.; FONTES, M. A. L.; OLIVEIRA-FILHO, A. T.; BOTEZELLI, L. Análise das variações florísticas e estruturais da comunidade arbórea de um fragmento de floresta semidecídua às margens do rio Capivari, Lavras-MG. Revista Árvore, v. 27, n. 2, p. 185-206, 2003. 
TER BRAAK, C.J.F.; PRENTICE, I.C. A theory of gradient analysis. Advances in Ecological Research, v.18, n.1, p.271-317, 1988.

VALVERDE, O. Estudo regional da Zona da Mata de Minas Gerais. Revista Brasileira de
Geografia, v.20, n.1, p.3-82, 1958.

VELOSO, H.P.; RANGEL-FILHO, A.L.R.; LIMA, J.C.A. Classificação da vegetação brasileira adaptada a um sistema universal. Rio de Janeiro: IBGE, 1991. 123p. 